\section{LAS RETÓRICAS DEL PÚBLICO. EL ESPACIO DE CONSUMO DEL ARTE COMO INSTITUCIÓN POLÍTICA*}

A la memoria de Alberto Sánchez Insúa

\author{
Fernando Bayón \\ Investigador Ocio y Desarrollo Humano \\ Universidad de Deusto, Avda Universidades 24, 48007, Bilbao \\ fernandobayon@deusto.es
}

\section{THE RHETORICS OF AUDIENCE. THE SPACE OF ARTS CONSUMPTION AS POLITICAL CONSTRUCTION}

\begin{abstract}
This article aims to show how the space for leisure practices in the art sector is a political construction. To do this, the essay focuses on public (art audience) as key concept. It argues that art audiences are critically engaged and politically significant communities, through which each society gives an institutional dimension to cultural practices. In dialogue with modern thinkers such as Adorno, Baudrillard, Warburg and Benjamin, or architects like Rem Koolhaas, the article presents audiences and publics from both a social and institutional points of view, understanding that the temporal and spatial dynamics behind their community boundaries are worth exploring. We think that there are at least two dominant forms of an emerging social rhetoric that are producing innovative ways of building the spaces for consuming cultural offer in the late modern society: we call them rhetorics of convergence and rhetorics of persuation.
\end{abstract}

KEY WORDS: Publics; social rhetorics; cultural leisure practices; contemporary art; public space; consumer society; cultural policy and arts programming; late Modern Society.

\section{Prólogo (etimológico)}

Elias Canetti, en su célebre ensayo Masa y poder, nos recuerda que algunos pueblos se imaginaron a sus muertos, o al menos a cierto número de entre ellos, como ejércitos combatientes. Así, entre los celtas de la tierra montañosa escocesa, el ejército de los muertos era designado por una palabra especial: sluagh. Esta palabra se reproduce en inglés como spirit-multitude o multitud de espíritus.

Aquellas mismas poblaciones reservaban otro término, ghairm, para significar "grito" o "llamada". Con su combinación, sluagh-ghairm, se producía la palabra con la que referirse al grito de guerra de los muertos. Más tarde se convirtió en la palabra slogan.

\begin{abstract}
RESUMEN: Este artículo pretende poner de manifiesto cómo el espacio de las prácticas de ocio cultural es una construcción política. Para ello, escoge como categoría central al público, en tanto formación comunitaria por medio de la cual cada sociedad institucionaliza de forma dinámica las prácticas de ocio asociadas a la oferta artística. En diálogo con pensadores como Adorno, Baudrillard, Warburg o Benjamin, se describen las dimensiones espaciales y temporales en que se desarrollan los vínculos comunitarios, específicos de la institución del "público" en el sector cultural. Para ello, el ensayo intenta identificar cuáles son las estrategias comunicativas que están produciendo esos espacios de presencia y esos tiempos de experiencia para las prácticas del ocio cultural en las sociedades del consumismo avanzado. Las he llamado retóricas de la convergencia y retóricas de la persuasión.
\end{abstract}

PALABRAS CLAVE: Público; retórica social; ocio cultural; arte contemporáneo; espacio público; sociedad de consumo; industria cultural; última modernidad.

Los gritos de combate de nuestras masas modernas, los eslóganes, derivan etimológicamente de los de los ejércitos de muertos de las tierras montañosas (Canetti, 1997, 38).

\section{El PÚBLICO, UN SÍNTOMA COMUNITARIO}

¿En virtud de qué procesos me convierto yo en público? ¿Qué tipo de compromisos adquiero en caso de confirmarse que formo parte de la principal institución comunicante entre el arte y la sociedad? ¿Esos compromisos me hacen responsable sólo ante la obra artística, porque ayudo a revalidar su autonomía objetiva, su adscripción a una esfera de resistencia que la impide corresponderse 
totalmente con ningún dominio de lo cotidiano? ¿0 quizás soy un actor de la estructura social en que me integro, y a lo que ayudo, en realidad, es a la tarea de modificación de la obra de arte en su intento de abrir una relación política en la comunidad?

Si nos olvidamos de sus decimonónicas acepciones -con sus marcadores de sangre, fe y raza, modélicamente estudiados por Ferdinand Tönnies en 1887-, la communitas postmoderna, abordada por Esposito, Nancy o Blanchot, es un vínculo que rehúye totalizarse en la posesión compartida de ningún bien (Blanchot, 2002). Se trata, paradójicamente, de compartir una falta o una deuda. Lo que nos une comunitariamente es antes lo que debemos, que lo que poseemos. El elíptico núcleo de la comunidad es la carencia, no la pertenencia. Frente a los fundamentalismos de toda laya que proliferan en la actualidad, las versiones postestructuralistas de la comunidad nos retan a pensar hasta qué punto sólo presentan síntomas comunitarios (Marinas, 2006) aquellas redes sociales que deciden compartir la apertura que nace de las inquietudes de la impotencia y no las clausuras arbitradas por las seguridades de la fuerza.

Una de las figuras que institucionalizan las prácticas de ocio de la ciudadanía tras la Modernidad es la figura del público. Ésta recoge la ambigüedad constitutiva de la experiencia del ocio en las sociedades del tardo-capitalismo: se aborde desde la filosofía, la pedagogía o la economía política, el ocio no puede ser desgajado de las categorias temporales; pero las posibilidades, experiencias y rupturas del tiempo, indicadas por el concepto clásico de ocio ya desde la ética nicomaquea de Aristóteles, obligan al pensamiento a practicar un giro espacial, sin el cual quedarian sin efecto los deberes y realizaciones del tiempo de ocio. Uno puede leer a Cicerón y entender que el ocio apunta a esa "digna apacibilidad" de quien, ni se deja arrastrar por la vorágine de la cosa pública, ni comete el deshonor de desentenderse por completo de los asuntos de Estado; para, acto seguido, comprobar cómo adonde apunta su visión, no es a una ética del reparto de las horas del día, sino a la necesidad de imaginar novedosamente el espacio público.

El ocio, por lo tanto, ha sido interpretado clásicamente como una de las dimensiones de la temporalidad, bien en clave positiva, como por ejemplo en la obra de Séneca, donde el ocio es la vida misma extendiéndose libre, feliz y sabiamente más allá de las meras fatigas de su auto- conservación y de los negocios imperiales, bien en clave negativa, en tanto magnitud variable que, por emplear el vocabulario marxista fijado en El Capital, sólo puede ser dilucidada una vez que hemos respondido antes a la pregunta decisiva: "¿Durante qué espacio de tiempo el capital tiene derecho a consumir la fuerza de trabajo cuyo valor diario ha pagado?". De modo que bajo el imperio del intercambio mercantil, el ocio es algo así como la sombra, o lo "otro", de la jornada laboral durante la cual el capital consume la fuerza de trabajo que ha adquirido para garantizarse una tasa de plusvalor (Marx, 2000).

Sin embargo, no se insistirá suficientemente en que la acepción eminentemente temporal del concepto de "ocio" no debe relegar a un segundo plano sus inseparables dimensiones espaciales. A cada momento a lo largo de una vida, las experiencias del ocio están siendo traducidas en y por el espacio. Pues el ocio es una urbanización de la temporalidad humana sometida, como todas, a límites y controles, planes y transformaciones. Una de esas instituciones que urbanizan las experiencias de ocio, que le dan una arquitectura fabricada de expectativas sociales y refuerzos comunitarios, es el público.

El concepto de público, especialmente en lo que hace a su relación con los productos artísticos y los espacios para su exhibición e interpretación, ha conocido una larga historia. Ya con el latino publicum se mentaba la multitud congregada afuera de los hogares. Un conjunto de personas a las que unía el hecho de que sus respuestas a la convocatoria de espectáculos coincidieran en el espacio y el tiempo. De ahi que fuese tratada como una respuesta única; pero en absoluto indiscriminada. La respuesta de la muchedumbre lo era casi siempre de una clase social, los plebeyos carentes de ciudadanía plena. Ellos detentaban sólo la presencia. Esa masa valía no por sus derechos políticos, sino por la fuerza de su mera actualidad. Cuerpo sin rostro, multitud medusea peligrosamente emancipada del clientelismo patricio, visceras de los ritos romanos de poder: les querian hacer saber de espectáculos antes que de igualdad política. El público era la forma que tenía el no-ciudadano de disfrutar de un cuerpo, de un nombre (cognomen), de un bien propios.

A diferencia de esto, la coincidencia espacio-temporal de una respuesta multitudinaria, a pesar de su importancia puntual en la cultura flashmob (convocatorias en las que 
el acto de dispersión del grupo encierra tanta importancia -y diversión- como el destello mismo de su reunión sorpresiva), no es ya condición imprescindible de la existencia del público. La fisicidad de su acepción perdió vigencia en el momento en que estas comunidades, incluidas las provocadas por espectáculos de corte escénico, pudieron tener lugar en ágoras virtuales. Presencia y corporeidad son dos condiciones que se divorcian en las comunidades de la era post-gutenberg. Puedes estar presente con tu cuerpo ausente. Pueden disponer de tu cuerpo precisamente para que no estés presente. $Y$ en nuestras rutinas digitales todos practicamos a diario mil maneras de estar presentes conservando nuestro cuerpo ausente (quizás, en una nube), así como otras tantas de experimentar la corporalidad dejando aparte la cuestión de la presencia.

Además, la modernidad nos ha enseñado a no separar el concepto social de público de dos fenómenos: uno, el desarrollo de cierto concepto jurídico de ciudadanía; dos, la diferenciación funcional del arte como sistema dentro de la sociedad moderna. Sólo cuando la sociedad estuvo informada por cierto sentido normativo de la igualdad política pudo surgir el concepto moderno del espacio público, al cual pertenecería, como una sinécdoque, el público que a nosotros nos interesa aquí, el convocado por el arte, en tanto sistema sometido, como todos, a la lógica de una clausura operativa y a las preguntas por su formación, límites, función, codificación y programación (Luhmann, 2005).

Creo, con todo, que hemos de mantener viva una sospecha: eso que, en el negociado del arte, Ilamamos "público", no es sin más un magnitud estadística, sino un tejido muy variable de fuerzas en tensión, cuya operatividad depende, tanto o más que de factores socio-económicos cuantificables, de una serie de retóricas y estrategias comunicativas que, especialmente cuando alcanzan niveles apabullantes de control sobre el sector cultural, pueden ayudarnos a rastrear la persistencia de ciertas lesiones políticas, típicas de la administración de los derechos de ciudadanía en puras democracias de consumo.

Lo que sigue es el intento de poner a prueba una serie de hipótesis, que podríamos resumir asi:

- El "público" es una de las principales instituciones de las prácticas de ocio cultural. Es la urbanización social de la libre programación individual.
- Deslizar el estudio de las prácticas del ocio hacia el interior de la institución del público, nos abre una perspectiva tan necesaria como innovadora: el análisis de la consolidación y gestión de nuevas forma de comunidad.

- El vínculo comunitario construido por la institución del "público" está sostenido por una tensión que es específica de la práctica de ocio: produce espacios de la presencia y tiempos de la experiencia.

- Pero el análisis no puede detenerse en estas constataciones. De las hipótesis anteriores se deriva una tarea crítica, de gran calado político: se trata de identificar cuáles son las fuerzas y poderes que están produciendo esos espacios de presencia y esos tiempos de experiencia.

- Por tanto, este ensayo obedece a una hipótesis que acaso antecede a todas las demás: ninguna comunidad $-y$ menos aquella que llamamos "público", en que la sociedad institucionaliza las prácticas de ocio cultural- surge "espontáneamente", ni se consolida "naturalmente". Hay siempre una política (o varias, en relación agónica) que la construye, la dirige y la soporta... hasta extinguirla.

\section{Del fiel al espectador, de Chârtres a Gehry}

El arte es el indigente mejor alimentado de los últimos dos siglos. El público nace, esta es también mi hipótesis, cuando el arte comienza a inventar la experiencia de lo que ya no puede ofrecer. Ya no es esencialmente medio de adoctrinamiento moral y de iluminación escatológica bajo el patronato enunciativo de ninguna religión, y tampoco un ítem más de la parafernalia exhibida por las casas reales como recurso de autojustificación y dominación sociales. El público es el suplemento profano, es decir, puramente social, de una expresividad artística que ha perdido sus suplementos metafísicos, para disfrutar (y padecer) una autonomía inédita. El público es la vida que le cabe a un arte sin coartadas de ultimidad, que se sacude sus viejas funciones cultuales para investirse con poderes intramundanos culturales.

El concepto de público, al menos tal y como se lo conoce desde el siglo XVIII, es una pieza clave, aunque a veces olvidada, de los complejos procesos de secularización que siluetearon la anatomía de la Europa moderna. Se volvió imprescindible consolidar una institución secular que amortizara toda una serie de innovaciones en el sector

ARBOR Vol. 188754 marzo-abril [2012] 409-426 ISSN: 0210-1963

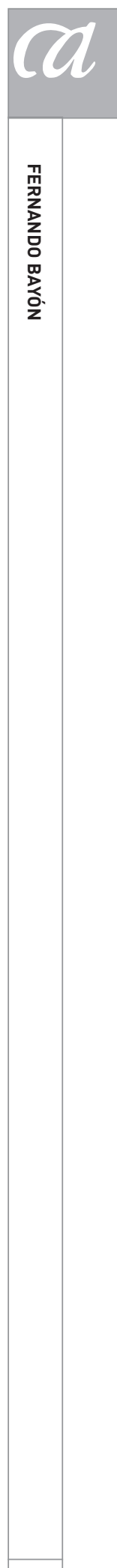


del arte (el artista como trabajador liberal; la profesionalización de la crítica; la expertización de los peritos y los tasadores, así como la proliferación de manuales teóricos que fijaban "objetivamente" el valor de las obras; el surgimiento de un mercado y una bolsa de cotización específicamente artísticos -en Londres-; la inauguración de museos enciclopédicos de administración estatal, etc.), que garantizara un grado políticamente controlado de entendimiento entre arte y sociedad, una vez que las bases ritual-religiosas y de mecenazgo de alto rango, que habian velado hasta entonces por su armonización, se hubieron debilitado.

En resumidas cuentas, el público nace cuando el arte deja de nutrirse de la idea del culto y comienza a nutrir la idea de humanidad. 0 , en terminología benjaminiana, el público surge en la época post-aurática del arte, cuando todo se puede decir artísticamente... porque es ya socialmente insignificante lo que el arte pueda decir. La catedral de Chârtres está encastrada en una ritualidad totalizadora, bien diferente de aquella en que se inserta un edificio de Frank Gehry, pues éste celebra la liberalidad de su posición de creador desde el interior de un sistema autónomo que la historia europea aún no les había producido, ni al arte ni al artista, a las alturas del siglo $\mathrm{Xl}$, siendo por tanto imposible que, ni los arquitectos como trabajadores, ni la arquitectura como disciplina, tuvieran el más remoto deseo de pertenecerle (tal y como sí hacen hoy, para disgusto de teóricos como Kenneth Frampton y solaz de alcaldes de la era postindustrial).

En adelante, he querido organizar mi exposición de tal modo que las hipótesis presentadas puedan ser contrastadas de la forma más plástica posible. ¿Cuáles son las fuerzas que subvienen a esa política social del ocio que llamamos "público"? Para responder a esta pregunta, he decidido imaginar dramáticamente esos poderes que condicionan y ordenan la formación de comunidades de espectadores, oyentes y lectores. Propongo resumir esos poderes en dos grandes construcciones retóricas. Por retórica entiendo aquí el orden de tropos, figuras, mensajes y estrategias comunicativas que articulan nuestros deseos, movilizando una serie de expectativas que, en primer lugar, ayudan a despertar nuestros intereses, y en segundo lugar, desplazan imaginariamente nuestra identidad hasta un lugar en que les espera una satisfacción o un cambio deseables. Para incidir en el planteamiento dramático, he convertido, a efectos metodológicos, a la una en antagonista de la otra... y las he llamado "retóricas de convergencia" y "retóricas de persuasión".

\section{Hacia las retóricas de conVergencia, por ORTega y Baudrillard}

Fue Ortega y Gasset quien en su ensayo de 1925 La deshumanización del arte, famoso, y merecidamente polémico, llamara la atención sobre la fuerza disociativa de que estaba revestida la obra de arte, que la llevaba a incidir sobre la masa de sus espectadores como un poder social que crea dos grupos antagónicos, que separa y selecciona en el montón informe de la muchedumbre dos castas diferentes de hombres. ¿Dónde localizaba Ortega el principio diferenciador entre ambas castas? Sencillamente, en el hecho de que cualquier obra de arte, particularmente las contemporáneas, gusta a unos más que a otros. Esta afirmación, que parece una banalidad de la que sólo por capricho se podría inferir una división en castas del sistema social, revela, sin embargo, cierto ojo. De que me "guste o no" una obra de arte depende que esté o no dispuesto a realizar el esfuerzo de trasladar el horizonte de significados de la obra hasta este otro horizonte social desde el que la contemplo (Bourdieu, 1998).

Ahora bien, hoy se ha derrumbado la confianza en que la distribución en castas de la sociedad de espectadores sea un procedimiento de carácter espontáneo, que depende de la índole del gusto de cada particular. El arte contemporáneo, por ejemplo, levanta en multitud de individuos la sospecha de que a ellos se les ha negado un órgano de comprensión de que otros sí parecen dotados. En auxilio de esos espectadores se ha desarrollado toda una tecnología compensatoria que echa paladas de autoestima sobre lo que Ortega -de nuevo con su retórica puntiaguda- llamó la oscura conciencia de inferioridad, que les hace sentirse un ente incapaz de modernos sacramentos. Quizás pueda rastrearse aquí alguna de las razones por las que el arte moderno ha perdido la capacidad de escandalizar por motivos estrictamente estéticos. El público que se considera culto es formalmente "inescandalizable", pues la propensión al escándalo echaría de ver una grave carencia de mundología en sus infraestructuras mentales. El público carente de formación e interés también lo es, pero por su indiferencia 
y la tranquilidad con que evacúan sus rechazos. Las tecnologías de control que operan sobre los espectadores más reacios consiguen que éstos amortigüen su propensión al escándalo, dejándola si acaso manifestarse en dosis irrelevantes, gracias a que proyectan la sensación de culpa e indignidad desde el aparato anímico del receptor hacia el aparato enunciativo de la obra recibida: hacia los desnudos de silicona de Ron Mueck y Charles Ray, hacia las vírgenes de estiércol de elefante de Chris Ofili (atento a los ritos de purificación hindúes), hacia los animales conservados en tanques de aldehído fórmico de Damien Hirst (atento al liberalismo anglosajón en materia de concordatos entre la zoé y el bios, entre la animalidad y la política, entre la basura y la cuenta corriente).

Hace ya algunas décadas, por tanto, que se ha puesto en cuarentena esa trascendencia que Ortega todavía otorgaba al arte, siquiera fuera a la hora de generar profundos antagonismos sociales. Una de las expresiones más influyentes del cambio en la influencia social del arte, a la sombra de un concepto de historia cada vez más desinvestido políticamente, la encontramos en Jean Baudrillard, el crítico que precisaba la época (ahora ella misma algo passé) del telemando, la miniaturización, la pantalla en lugar del espejo y la terminal de múltiples redes en lugar del actor dueño de una escena. Tras leer a Baudrillard, el relato del Arte dividiendo al mundo en dos bandas, élites y masas, parece un cómic pintado en sepia. Para oponerse al otro antes hay que reconocerlo en su existencia, investirlo de un poder. Pero cuando cada individuo se resume en un punto hiperconectado telemáticamente, imaginar al otro es imposible, además de inútil. ¿Para qué habré de imaginarlo si puedo trasportarme hasta él salvando tecnológicamente todas las distancias antaño sublimadas mediante la imaginación, si puedo producir su presencia y depositar la mía en su bandeja, con el click de los nuevos medios? Las ilusiones del instantaneísmo tecnológico no dejan demasiado espacio para el viejo arte de la ilusión.

Hemos olvidado el arte de la desaparición (el arte a secas siempre ha sido una poderosa palanca de desaparición: poder de ilusión y de negación de lo real). Saturados por el modo de producción, debemos recuperar los caminos de una estética de la desaparición. La seducción forma parte de ellos: es lo que desvía, lo que aleja del camino, lo que hace ingresar lo real en el gran juego de los simulacros, lo que hace aparecer y desaparecer. Casi podría constituir el signo de una reversibilidad original de las cosas. Cabría defender que antes de haber sido producido, el mundo ha sido seducido, que sólo existe, al igual que todas las cosas y nosotros mismos, por haber sido seducido. Extraña precesión, que sigue planeando actualmente sobre toda la realidad: el mundo ha sido desmentido y desviado originalmente. Es imposible que jamás se verifique o reconcilie consigo mismo, ya que en su origen ha sido desviado (Baudrillard, 1997).

Baudrillard hace memoria del arrobo luciferino de nuestra excentricidad constitutiva y sin remedio, bien aprovechada por el mercado del arte, que sacude esquizofrénicamente al público, ya con una proliferación obscena de sistemas de interpretación que, códigos en ristre, por todas partes quieren desnudar la verdad y emitir significados (sin cacarear los cuales no eres nadie); ya con un derrotismo de la jouissance que le disuade de intentar redimir las apariencias mediante la gracia de buscarle ningún sentido (el goce literalmente superficial ocupa el lugar del sentido).

Pero las palabras de Baudrillard apuntan a algo más misterioso, evocar la seducción como origen de toda antropología equivale a despertar lo que quisiéramos mantener narcotizado: nuestro destino público de sujetos pasionales...

\section{DE LA INTIMIDAD INSOSTENIBLE A LA SOSTENIBILIDAD ÍNTIMA}

Las retóricas de convergencia se ejercen sobre el conjunto de los individuos como una violencia virtual. Esto es, permaneciendo ausentes de los lugares y los momentos en que triunfa su coacción. Extraordinariamente efectivas, pasan en cambio tan desapercibidas como la mano invisible de Smith, la sonrisa del gato de Cheshire de Lewis Carroll o la desnudez del rey de Andersen. Invisibles por estar totalmente a la vista. Invisibles por su pura evidencia. Tan invisible como los olvidos de un museo, esos campos de concentración de la desmemoria, como viera Benjamin. Imperceptibles por la naturalidad con que las percibimos. Discretas por la fuerza de su obviedad.

Este rasgo de su conducta tiene igualmente consecuencias de gran alcance para la conformación del público, pues ocurre que no sólo ellas disfrutan de la invisibilidad propia del temor, la redundancia, el tópico, el clisé o el prejuicio

ARBOR Vol. 188754 marzo-abril [2012] 409-426 ISSN: 0210-1963

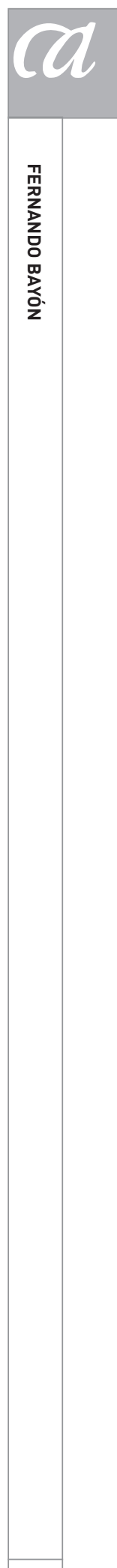

413 
(Nietzsche creía que toda palabra lo era), sino que condenan a la invisibilidad a los individuos más sensibles a su gramática comunitaria (el fan, el suscriptor, el turista, el socio, el simposista).

Para entender mejor el modo como las retóricas de la convergencia inhieren en la identidad del público, me gustaría traer a discusión dos grandes paradigmas retóricos, desde los que irradian algunos de los conglomerados de proposiciones de mayor impacto y tráfico sociales: la intimidad y la sostenibilidad.

La subjetividad contemporánea sufre, y disfruta, de un continuo desplazamiento. La búsqueda de la conformidad y sanción sociales, de la que depende directamente nuestra supervivencia, sumerge al sujeto en una tupida red de relaciones de sanción, aprobación y dependencia respecto a algo exterior. ¿Pero cómo se construye ese exterior? ¿Cuál es la naturaleza de sus referentes y de sus autoridades? ¿Y cuáles las vías de acceso a ellos? Desde luego el universo $w w w$, o internet como nuevo ágora planetaria, nos da una pista al respecto. En primer lugar, fijémonos en que la voluntad de hacer pasar a internet por un ágora, cuando no por un universo entero, es un ejercicio decididamente atrevido desde el punto de vista semántico. Llamar "universo" a algo que pone todos los medios funcionales para no merecer semejante metáfo$\mathrm{ra}$, nos demuestra hasta qué punto las administraciones públicas y los intereses privados venden la red repartiendo mitos que se desconstruyen a sí mismos con enojosa facilidad. Internet, su abismo imprivatizable, no quiere merecer determinadas metáforas: ni la de plaza, ni la de mundo, y menos la de universo. Como sustituta de las clásicamente establecidas, la sanción social para la subjetividad se obtiene cada vez más en plataformas integralmente tecnologizadas, que proporcionan soportes difusos para la (a)probación del yo, en la modalidad de repetidos estallidos de intercambios, que es el eufemismo con que se describe hoy el viejo verbo capitalista "comprar".

El lema inicial (estamos hablando de otro big 1989) de aquel localizador de recursos [URL] al que se asignara un protocolo de transferencia de hipertexto [http] era Enquire Within Upon Everything, algo así como interroga desde dentro sobre cualquier cosa. Esa herramienta, originalmente diseñada para consumo interno de militares y científicos a la búsqueda del hipertexto simultáneo, ha acabado con- virtiéndose popularmente, tanto o más, en algo en donde uno se confiesa, que en algo a lo que uno interroga. Es decir, internet ofrece el mundo supuestamente ideal que habitar a todos aquellos convencidos de que Richard Sennet acertaba con su diagnóstico, realizado años antes de la extensión de la WEB (Sennet, 1977), según el cual la intimidad completamente vaciada conduce a comunidades destructivas (destructive Gemeinschaft).

Una genuina mutualidad resiste mal un bombardeo de intimidad, venía a decir Sennet. Vaciar mi intimidad, con todos sus espeluznantes detalles, en un mismo vertedero ( 0 , más románticamente, en un solo hombro) puede resultar un exceso indigerible incluso para el vertedero más paciente. La intimidad vaciada sobre un solo receptor puede llegar a constituir un tipo abusivo y patológico de comunicación, capaz de hacer quebrar la más sólida red de confianza. A la hora de compartir la subjetividad, ya no hay por qué asistir al eterno choque de dos proyecciones personales distintas que han de aceptarse por el mismo gesto con que pretenden afirmarse. Internet ofrece un inmenso alivio para este problema. Pues se trata de un mundo en que estos vertidos de intimidad, abusivos, contaminantes, postburgueses, lejos de destruir comunidad física alguna (como ocurría con tanta frecuencia en el domicilio conyugal... o la escalera vecinal), ayudan antes bien a reforzar y hacer que prolifere su sistema mismo de relaciones (del chat y el microblogging, a la nueva diplomacia semipública de las redes sociales).

Que lo que el estrés de la vida social moderna ha desunido lo vuelva a unir la fracturada y californiana diplomacia twitter: es el triunfo de la interfaz anti-narrativa (sólo 140 caracteres), de la retórica de la "cuenta", el "seguimiento" y el "dominio". Ese es el lema de campaña de infinidad de familias que resucitan como estructuras comunicativas gracias a los nuevos medios de internet. De infinidad de aulas de juveniles camaradas que vuelven a recolocar nostálgicamente sus pupitres en el espacio virtual. En internet el viejo sujeto deviene en una "cuenta", encarnada por medio de un "avatar", dentro de un "dominio", con el fin de resucitar estructuras interpersonales cuya experiencia parecía imposibilitada por la modernidad distante, racionalizadora y antiemotiva precedente. La cuenta: la palabra tiene, no por nada, una acepción económica adherida a lo que no es sino que el fantasma de una acepción narrativa desvencijada hace ahora un siglo (en el modernismo de 
Joyce, Pessoa, Kraus o Musil). El dominio: un término que promete tanto la intervención controlada en un espacio, cuanto una práctica de la voluntad libre.

Estamos ante la posibilidad de construir una mutualidad virtual, discretamente indiscreta, un cálido high-tech donde podemos distribuir -algunos dirian borrar, y creo que equivocadamente- nuestra intimidad en diferentes consignas sin necesidad de depositarla, con todo su catálogo de insuficiencias, en un único fondo de inversión. Logrando así que la subjetividad encuentre nuevas ocasiones tanto para su enmascaramiento (nick) como para su compromiso (la discriminación del tweep frente al twitterian). Es la lógica del avatar: acceso/velo. Identidad por la no identificación. El último repositorio del prósopon.

Podriamos quizás preguntarnos si, frente a las letanías postfoucaultianas acerca de la muerte de esa invención reciente que es el hombre -ya saben, el hombre se borraría, como en los límites del mar un rostro de arena (Foucault, 2006, 375)-, no existe de la mano de las tecnologías asociadas al universo web un nuevo boom del yo, que encuentra cada día nuevos topoi a los que autotrasplantarse. Nuevos lugares como los foros, esos libérrimos campings del yo, en los que celebrar la propia diversidad sin ejes cartesianos. Claro que nadie puede olvidar que todos esos campings de la subjetividad que ofrece internet exponen a aquélla a otras tantas visibilizaciones y dependencias de difícil gobierno o dominios. La aparente expansión y celebración del yo es radicalmente inseparable de un creciente censo de dispositivos de vigilancia, que ya no son los típicos de un capo estalinista, sino los de un pirata informático, que puede trabajar por placer predatorio o bajo instrucción de grandes corporaciones, capaz de hacer un mapa de nuestra subjetividad pinchando en el cubo de la basura de nuestros anonimatos y trasvestismos digitales. Rastreando las huellas del consumo web que se protege bajo mil veladuras (im)personales.

Hablamos de diseños tecnológicos que, al modo de telas de araña planetarias, excitan por doquier energías que ellos se encargan asimismo de dirigir y extinguir igual que un ¡bravo! Por encima de otras consideraciones, las retóricas de convergencia ven lo múltiple bajo el signo de la unidad, lo disperso a la luz de la concentración y la diversidad como sombra a extinguir por la luz de la coincidencia. La demanda converge bajo el peso de un lenguaje que se ha especializado en desarrollar los aspectos sintácticos o conectivos de su gramática. El público no es el producto del roce de cuerpo con cuerpo sino de la coincidencia perfecta, una armonía acumulativa preestablecida, de mónada con mónada, de soledad con soledad, de momento con momento, de integrado a integrado (según Umberto Eco), en un vasto universo de placer lleno de pseudo-rupturas subjetivas. El capital elimina los matices de una cultura, escribía Don DeLillo en su epílogo, titulado Das Kapital, a ese monumento novelístico que es Submundo.

La inversión extranjera, los mercados globales, las adquisiciones corporativas, el flujo de información mediante los medios de comunicación transnacionales, la influencia moderadora de un dinero electrónico y un sexo ciberespacial, dinero que nadie toca y sexo seguro mediante ordenador, la convergencia del ansia de consumo: no es que las personas ansien necesariamente lo mismo, sino que ansian el mismo abanico de opciones. Algunas cosas se marchitan y palidecen, se desintegran estados, cadenas de montaje acortan sus turnos e interactúan con cadenas de otros países. Esto es lo que el deseo parece exigir. Un método de producción que satisfaga a la medida de las necesidades culturales y personales, y no las ideologías de uniformidad masiva propias de la guerra fría. Y el sistema finge aceptarlo, volverse más flexible e ingenioso, menos dependiente de categorías rígidas. Pero incluso a medida que el deseo tiende a especializarse, a volverse sedoso e íntimo, la fuerza de los mercados convergentes produce un capital instantáneo que atraviesa los horizontes a la velocidad de la luz, lanzados hacia una igualdad furtiva, un cepillado de detalles que afecta a todo, desde la arquitectura al ocio pasando por el modo en que la gente come y duerme y sueña (DeLillo, 2000).

\section{5. ¡Póngase la La mona LISA a SUS espaldas! (O ¿CUÁNDO SE HACE DESEABLE UNA EXPERIENCIA?)}

De este modo, las retóricas de convergencia no aplican su instrumental sobre las obras de arte con miras a allanar el camino que habrá de recorrer cada individuo para llegar a ciertas convicciones propias. Dirigen sus procedimientos a inculcar convicciones estereotipadas (simposios, programas, eslóganes, incluyen información indistinguible de la publicidad), que ahorran el esfuerzo de recorrer aquel

ARBOR Vol. 188754 marzo-abril [2012] 409-426 ISSN: 0210-1963

西


camino. Las retóricas de convergencia son una serie de procedimientos dirigidos exclusivamente a asegurarse que el sujeto llega hasta la obra de arte, rechazando toda responsabilidad acerca de lo que aquél pueda hacer con ella a partir de ese momento, salvo a la hora de garantizar que se va a disfrutar de una auténtica experiencia. Terminará por resultar conmovedora la aparición de un gestor cultural que ofrezca experiencias realmente inauténticas. La jerga de la autenticidad invade el marketing de las experiencias artísticas igual que las cadenas distribuidoras de burritos, dim-sum y sopas thai, y lo hace curiosamente en la época en que, por su parte, la obra de arte se ha emancipado completamente de las supersticiones de la autenticidad y la originalidad, por apuntar al célebre diagnóstico benjaminiano sobre la era de la reproductibilidad técnica.

Dominick LaCapra, en el contexto de los estudios históricos, afirma de un modo muy perspicaz cómo la experiencia es aquello que permanece o queda cuando el sentido y el lenguaje no agotan sus objetos (LaCapra, 2006, 62-72). Como si el moderno concepto de experiencia histórica fuera la versión secularizada de una teología negativa, cuyo objeto sólo puede definirse por lo que no es, LaCapra logra hacernos entender que la experiencia queda bien caracterizada no tanto por las efusivas retóricas de la plenitud cuanto por las críticas retóricas de la impotencia. ¿Cuándo se hace deseable una experiencia? No cuando implica, psicológicamente, la absoluta transparencia de la vida íntima $u$, ontológicamente, la desocultación del ser de las cosas. La experiencia deseable es aquella que permite acceder a un estado de conciencia en el que nuestras insuficiencias quedan expuestas, de tal forma que nuestra iniciativa y creatividad no caen asfixiadas bajo el peso de la fusión con ningún objeto, sino estimuladas por la visión de ese lapso, de esa fractura, de esa distancia, que ella misma nos ha producido (Bayón, 2010).

Hemos de comportarnos críticamente no tanto con la noción en sí de experiencia, cuanto con la comercialización económica, social y política de que es paciente hasta convertirla bien en un puro bien de cambio, bien en pasto de seudopensamiento new age. Ella misma se ha convertido en paciente de aquella ideología que Walter Benjamin detectara en las grandes Exposiciones Universales de finales del XIX: todo se ve, nada se toca, aprenda Vd. que la experiencia es mero precio, solo un valor de cambio. Claro que esa ideología se disfraza hoy de lo contrario (me refiero al nuevo dogmatismo de la interactividad) para preservar, en el fondo, la lógica mercantil con que se trafica con las experiencias del ocio, convertidas las más de las ocasiones en los ocios de la experiencia.

Si vence esa lógica, quedaría solo retratarse ante el retrato. Este síndrome de La mona Lisa es el tótem de la recepción del arte, la meta social felizmente asumida por el "gran público", el límite del pathos turístico en las relaciones con las obras: ipóngaselas de fondo! La fetichización turistica de la obra de arte convierte en irrelevantes la pertenencia del sujeto a uno u otro sistema político, económico y cultural. Hasta el punto de que dichos marcadores queden desvaídos, sean indiferentes, caigan de brazos rendidos tras probar el láudano del éxito mundialmente participado, pues ¿qué es el Arte, con mayúsculas de turoperador, sino todo aquello que un turista, chino o tejano, está en condiciones de exhibir a sus espaldas o en el fondo de escritorio de su Mac?

Esto da lugar en la práctica a un arte políticamente inane y críticamente despotenciado. Un arte, además, sin grandes convenciones que, como dioses únicos o demonios rectores, consagraron en buena medida la producción artística en otras épocas. Hoy conviven en su territorio tendencias expresivas vecinas de una seudodivergencia que es el patio planetario donde se suscitan rifirrafes en línea, de calculada rentabilidad. Cada una de ellas pretende elevar a la altura de la mirada del público una concepción diferente del mundo, o su simulacro mercantil. La armonía de los dioses en el valhalla del arte se ha roto. Pero los dioses ya no compiten trágica y encarnizadamente a golpe de programa artístico, blandiendo unos frente a otros sus ultimísimas estéticas o novismos, oponiendo competitivamente sus teorias acerca de la creación. La famosa contienda de los dioses es una leyenda weberiana cuyo buen tono intelectual se vuelve cada vez más difícil de leer. Y si el público, en esta deflación generalizada del olimpismo de los dogmas artísticos, en este escenario antitrágico del mercado del arte, en medio de esta atonía y plastificación del escándalo, siente nostalgia del paraíso del que huyeron los dioses (quizás, a la postre, un gueto como otro cualquiera), y emprende la búsqueda de huellas interpretativas con validez más general, no encontrará nada... o quizás demasiado: un nuevo academicismo que se hace pasar comercialmente por la última apoteosis de lo ecléctico. 
Ya no interesa fabricarnos un momento inequivocamente nuestro. La impureza ha sido bendecida (en inglés). Para que la mirada sea envuelta en el patchwork de los revivals. Al arte no le obsesiona construirse un presente, sino que el tiempo se hojaldre: un cronoecumenismo bajo el signo del arte. Esto es sobre todo válido para el período posterior a la coronación histórica del gran arte conceptual, allá por el primer lustro de la década de los setenta, cuando creadores como Douglas Huebler, Joseph Kosuth y Robert Barry fueron los últimos en autoconstituirse explícitamente en vanguardia, cerrando un gigantesco círculo de alrededor de seis décadas cuyo centro seguía siendo, después de todas las vueltas de noria, Marcel Duchamp'.

A partir de ellos, se hace más claro que el arte quiere hacerse pariente óntico del tótem de la variabilidad social: la información. Y que, como ésta, desea la volatilidad y un estatuto de antiforma carente de estructura, permanencia y límites. Sobre las pertinaces ruinas posrománticas de la forma artística está ayudando a definir una época capaz de experimentar una delectación neobarroca ante formas líquidas, voltarias, etéreas y de una volubilidad hipertextual despampanante: arte 2.0 (¿o es ya 3.0?). Quiere, al igual que la información hoy, constituir su ser a la manera de un esparcimiento aéreo de sustancias efímeras. Y, como la información, el arte quiere ser pasmoso aunque lo que distribuya sean silencios. Desea ser hedonista aun cuando lo que esparza sea crueldad.

\section{LAS RETÓRICAS DE CONVERGENCIA Y LA SOCIALIZACIÓN TOTAL, SEGÚN AdORNo}

Decía Northrop Frye que "los juicios de valor arrastran consigo, como su sombra, por así decir, un sentido de lo socialmente aceptado" (Frye, 1973, 98). Actualmente, en que el statu quo de la crítica como emisora sistemática de juicios de valor representa para muchas personas el no va más de cierta liberalidad del "gusto del discurso" antes que del "discurso del gusto", esta ansiedad valorativa que encoge el alma del público facilita extraordinariamente el trabajo a las retóricas de convergencia. Les regala la imagen fiel de lo que es aceptable para los grupos sociales. Dicho de otro modo: les dice en qué fallan. Las retóricas de convergencia, y la publicidad lo sabe demasiado bien, someten a examen general los prejuicios del grupo, impidiendo simultáneamente que los resultados de dicha prueba redunden en beneficio de sus miembros, pues no hacen derivar de ella consecuencias formativas para los individuos. Son discursos que obtienen, a cada momento, la placa radiográfica de las angustias de un grupo, sin preocuparse de proporcionar al consumidor las alternativas con que deslegitimar las estructuras sociales de las cuales esas angustias han sido arrancadas. El estrés refuerza el sentido y la vida del agente que lo produce.

Las retóricas de convergencia convierten la obra de arte en una cosa a enjuiciar a beneficio de la exaltación del ego, poniendo lejos del alcance del público la idea, mucho más profunda, de que todas la obras de arte son poderes a poseer, que nos incumben. Ocurre que, al emitir un juicio de valor, quedan desnudos nuestras lagunas y prejuicios, y esa vulnerabilidad conviene estratégicamente a la retórica de convergencia para continuar preservando su control sobre el grupo social, sobre el público. En demasiadas ocasiones, dirigir una crítica a una institución cultural es como pretender ofender a un voyeur regalándole un desnudo.

El espectador es una institución histórica cuya existencia depende casi siempre de la efímera producción de situaciones dentro de las que se le hace aparecer $y$, lo que es igual de importante, desaparecer. De este modo, cada cita con el público supone la inminencia de su borramiento (nuevamente, la cultura flashmob ironiza sobre estos procesos de aparición/desaparición). Sería equivocado dejar de pensar que lo que nos permite seguir hablando del público no es su condición de entidad consumidora sino, más precisamente, su infatigable vocación como institución consumida.

"Ha llegado a ser obvio que ya no es obvio nada que tenga que ver con el arte, ni en él mismo, ni en su relación con el todo, ni siquiera su derecho a la vida", decía Adorno en la primera línea de su Teoría estética (Adorno, 2004, 9). En este libro tiene su encaje más serio gran parte de lo que he querido comprender bajo el nombre de retóricas de convergencia. En primer lugar, Adorno defiende que el arte sólo puede reconciliarse con su propia existencia volcando hacia el exterior su propia apariencia, "su hueco interior". Con el avance en la organización de todos los ámbitos culturales, crece el deseo de señalarle al arte su lugar en la sociedad, tanto teórica como prácticamente. $Y$ tal como apunta maliciosamente el autor, de esto se encargan innu-

ARBOR Vol. 188754 marzo-abril [2012] 409-426 ISSN: 0210-1963

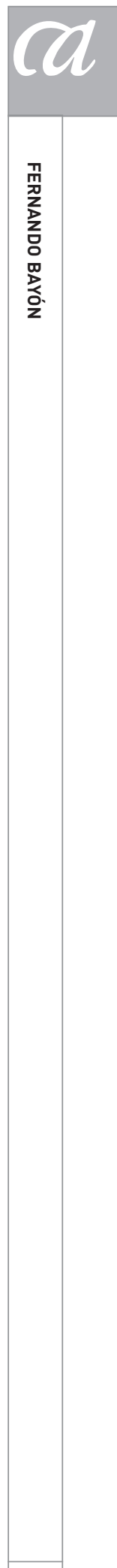

417 
merables mesas redondas y encuestas. Pero lo más decisivo no es esto, lo decisivo es que una vez se ha comprendido que el arte es sobre todo un hecho social, la localización sociológica se siente superior a él y manda sobre él. Se presupone entonces la primacía de la administración, del mundo administrado, implícitamente también frente a todo aquello, lo subjetivo, que no quiere ser atrapado por lo que Adorno denomina la "socialización total": el momento en que todos convenimos inconscientemente en que el acento de las obras de arte hay que desplazarlo hacia su consumibilidad, decidiéndose de antemano, y de manera casi siempre conformista, que hay que hacer trizas y diseminar la ambigüedad constitutiva, pero poco comercial, de las construcciones estéticas. ¿Dónde reside esa ambigüedad? En que -siguiendo a Adorno- son capaces de codificar la abdicación del sujeto debilitado, convirtiendo en su asunto más propio el extrañamiento absoluto de la humanidad moderna; $y$, al mismo tiempo, de anticipar la imago de un estado más reconciliado, esperanzador y justo.

Seguiría valiendo, por tanto, la célebre inventiva de Eduard Steuermann de que cuanto más se hace por la cultura, tanto peor para ella. Si no fuera porque con este adagio se frotan hoy las manos todos aquellos buenos neoliberales contra los que, muy precisamente, está dirigido.

\section{Retóricas de la persuasión: la caja de herRamientas de Aby Warburg Y Walter Benjamin}

Inspirándome libremente en la obra del malogrado pensador y poeta italiano Carlo Michelstaedter, y más concretamente, en su celebérrima tesi di laurea "La persuasión y la retórica", quiero introducirme ahora en la antagonista de la retórica de la convergencia: la retórica de la persuasión. Conviene de entrada aclarar cuál es el sentido que concedo aquí a la palabra "persuasión" (los lectores de Austen partirán con alguna ventaja). Me refiero bajo ese término a las estrategias lingüisticas que luchan contra el ser inercial de la humanidad moderna, que introducen una cuña crítica en su amnésica aceleración del tiempo, que se defienden de los cambios fetichistas de un presente vacío por otro presente vacío, en una aventura infinita de insatisfacciones programadas y alentadas comercialmente. Retórica de la persuasión -fundiendo en una sola expresión lo que para Carlo Michelstaedter eran dos contrarios- es el orden del lenguaje en que se mueve aquel que tiene el valor de arrancar de sí la trama de cosas queridas, por manidas, dándose permiso para poseerse a sí mismo en la actualidad del presente, y poniendo su identidad en juego dentro de un futuro que no esté administrado por esa mesotés (medianía) que es el Gran Hermano que regala palabras de apariencia absoluta y resplandeciente, de eficacia inmediata y pavloviana, que, a cambio, no tienen ni el más oscuro instinto de vida (Michelstaedter, 2009).

Llamaré, por tanto, retóricas de la persuasión al conjunto de procedimientos destinados a la adquisición de un lenguaje común entre el público y la obra de arte, bien entendido que este lenguaje no es una llave de acceso mágico a las obras, ni clase alguna de ábrete sésamo estético, sino más bien el ensayo que -en expresión de Adorno- permite descubrir generosidad en la obra esquiva. Se trata de una lengua cuya gramática no será la misma que la de aquel metaforismo prefabricado en que eran expertas las retóricas de convergencia. Ser competente en este lenguaje significa que el público desentumece su imaginación, contraída por los instrumentos de convergencia en los moldes enfáticos de las coyunturas sociales, permitiéndole adoptar formas nuevas y elásticas, conforme a un dinamismo que hace justicia a su carácter fórico, evasivo, asociador, político.

Quiero apoyar mi exposición del funcionamiento de las retóricas de la persuasión en la obra de dos pensadores: Aby Warburg y Walter Benjamin. Comencemos por la imbatible figura de alguien cuya obra maestra no es un libro, sino una biblioteca. "Biblioteca para la ciencia de la Cultura", más tarde Instituto Warburg, trasladado a Londres en 1933 con la llegada del nazismo, cuyo origen habria que indagarse en la adolescencia de Aby, hijo de banquero, cuando vendió su progenitura al segundo, Max, al precio de una promesa: que le facilitara todos los libros que le fuera pidiendo. La aportación de Warburg a la Historia del Arte difícilmente puede reducirse a su célebre rechazo del método estilístico-formal dominante hacia fines del XIX, por más que expresara siempre una "honesta repugnancia" frente a la ästhetisierende Kunstgeschichte (historia estetizante del arte), unida a una vindicación de los aspectos programáticos contenidos en las obras, vindicación que obligó a un decisivo giro icónico en la historia del arte. 
Por alambicado que nos resulte su traducción, hemos de cartografiar muy sucintamente el léxico de Warburg, comenzando por una de sus palabras más usadas: Nachleben, cuyo significado se acerca al de "supervivencia", e incluso al de "vida póstuma". Aby Warburg entiende la cultura como un proceso de Nachleben. Es decir, de posterioridades, transmisiones, recepciones, super-vivencias y polarizaciones. Esta visión del carácter póstumo de la cultura vuelve perfectamente comprensible por qué su teoria de la memoria social se concentró tan obsesivamente en el problema del tiempo: historiar los procesos de recepción del arte obliga a imaginar el tiempo organizándose en constelaciones de rupturas, saltos, metamorfosis y recurrencias, que dinamitan por completo las habituales concepciones lineales de la historicidad.

Siguiendo de cerca a Gombrich, el responsable de una conocida biografia intelectual del autor de El renacimiento del paganismo, podria decirse que Warburg puso en práctica una teoria patética de la memoria social. De hecho, emplea el término Pathosformel (fórmula del pathos o fórmula emotiva) como uno de los núcleos temáticos de sus estudios del Renacimiento (Warburg, 2005). Carlo Ginzburg, en un ensayo de referencia, ha puesto en claro cómo a través de la noción de Pathosformeln las representaciones de mitos legadas por la Antigüedad eran entendidas como -y cita al propio Warburg- "testimonios de estados de ánimo convertidos en imágenes, en los que las generaciones posteriores buscaban las huellas de las conmociones más profundas de la existencia humana, de acuerdo a la mímica y los gestos como rastros de violentas pasiones experimentadas en el pasado" (Ginzburg, 2008, 51).

Las implicaciones de la noción de Pathosformel son, a partir de aquí, mucho más profundas. Estas pautas representativas son el reservorio dinámico de una experiencia emotiva de la trasmisión cultural, que hace hincapié en una suerte de biología de la memoria, en la medida en que ésta no es una exquisita facultad de la consciencia sino la capacidad explosiva de reaccionar ante la huella de un acontecimiento. Huella o incisión sobre la materia viva que Warburg, siguiendo la oscura Mneme de Richard Semon, interpreta como energía, potencia, y a la que denomina "engrama". Los símbolos son para Aby Warburg acumuladores de una energía derivada de experiencias básicas, intensas hasta lo orgiástico, a cargo de humanidades paganas primitivas, entregadas a unas pasiones cuyos éxtasis quedaron acuñados en esos condensadores de oleadas de entusiasmo y peligro ritual que son los símbolos: "En esto reside la importancia de la antigüedad griega dionisíaca para nuestra civilización occidental -dice Gombrich-. En su mito se encierran los extremos de la emoción y el auto-abandono que, probablemente, horroricen al hombre moderno, pero que conservados en los símbolos del arte, contienen los mismos moldes de la emoción que bastan para posibilitar la expresión artística" (Gombrich, 1992, 228s.).

¿Por qué reivindicar el método de Aby Warburg en este contexto? Pensemos en que este experto en políticas póstumas del arte que fue Warburg pasa por evitar la ganga del "junguianismo", radicalmente incompatible con él. El símbolo o engrama es una carga de energía latente; pero en sí es neutra, sólo a través del contacto con la voluntad selectiva de una época se "polariza" en una cualquiera de las interpretaciones de que es potencialmente capaz. Hay, por tanto, en Warburg una fastuosa dinamogramática (sic) de la historia del arte que, primero, huye de la distinción esquizoide entre forma y contenido $y$, con el mismo gesto, aparta de sí la fractura cultural entre arte y ciencia, entre la palabra que canta y la que recuerda (Agamben, 2008, 149). 0, como escribe Georges Didi-Huberman, "siempre, ante la imagen, estamos ante el tiempo" (Didi-Huberman, 2005, 11; 2009).

La iconología -un término que, Panofsky mediante, ha acabado venciendo en la subasta de nombres para una disciplina sin nombre (Agamben, 2008, 127ss.)- abre la esperanza de unas relaciones nuevas entre el tiempo y la recepción, entre la historia y el público, al vindicar la vida póstuma de las imágenes, a las que no se deja operar tiránica, formal y vaciamente, antes bien se descubre en ellas la valencia de fuerzas emotivas latentes que interpelan a todo tiempo futuro, obligándolo a responder ante esas Pathosformeln conforme a un estilo, cualquiera que fuere, el de la represión, la liberación, la sublimación o la explosión, que lo retratará. Esa corresponsabilidad ante una historia (en su vocabulario, ante el dinamograma de la historia) pone en evidencia la "psicología" de las fuerzas y fracturas de cada momento, de cada presente.

Warburg nos ofrece una sismografía de las necesidades vitales de cada período histórico, que queda así psicológica y políticamente retratado en su proceder como heredero de

ARBOR Vol. 188754 marzo-abril [2012] 409-426 ISSN: 0210-1963

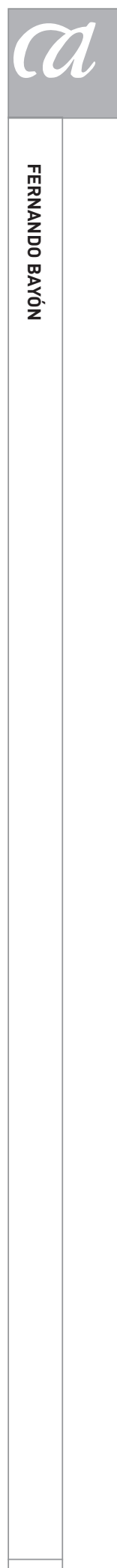

419 
tensiones que, como dice Agamben, exigen una "confrontación, mortal o vital según los casos, con las tremendas energias que se habian fijado en aquellas imágenes, que guardaban consigo la posibilidad de hacer retroceder al hombre en una estéril sujeción o bien de orientarlo en su camino hacia la salvación y el conocimiento" (Agamben, 2008, 137). Aby Warburg derrumbó la política del Zeitgeist, esa concepción en parte heredada de Winckelmann y Hegel, según la cual existe algo así como "un espíritu de época" que se reparte homogéneamente igual que una cosmovisión por las distintas esferas de intervención social. Benjamin admiró muy precisamente este rasgo de Warburg, alguien favorable a la ruptura con cualquier tratamiento de la tradición inspirado en generalizaciones. La interacción y degradación de formas y contenidos en un shock de tradiciones de recepción, de constelaciones de sentido, era mucho más afín a su estrategia. Los entornos culturales, o los individuos, están inmersos en situaciones de elección y conflicto, no bajo el imperio generalista de leyes predeterminadas ni bajo la negra noche de ninguna Geistesgeschichte (historia del espíritu). Al dar vida a un motivo tradicional, cada sociedad, cada individuo, deberán salir a la búsqueda de un lenguaje y un vocabulario propios con que expresar su (re)visión. Esa elección será sintomática de sus fuerzas y sus fracturas.

Qué distante está el Begriffssystem warburguiano del melodrama social de la trasmisión de la obra de arte inspirado en la propaganda, la información redundante, la influencia de gurús especializados, los latiguillos valorativos, los tópicos que introducen el pensamiento en la horma de las frases hechas, la cultura de camisa de libros y tertulias corporativas, las calculaciones estadisticas, así como de esa institución ontopublicitaria que es la televisión. Toda esa retórica forma la imaginación ortopédica del público, y ha hecho también de él un órgano ortopédico con que la sociedad se enfrenta al arte. Dicho de otra manera, ese melodrama protagonizado por tópicos y prejuicios de toda índole sobre el escenario de la psique del espectador puede que no careciera de interés si dichas tecnologías no impidieran que sus "actores" se sometieran al poder crítico, probatorio, mezcla de pasión y desconcierto, de que está revestido un encuentro político con el arte. Pues, si lo impiden, el lugar que habría de ocupar una toma de conciencia de la perspectiva institucional desde la que nos está permitido mirar y comprender el arte, lo ocupará una ciega connivencia con una determinada fábula de consumo, con la enésima operación de marketing al servicio del desarrollo del lucro. La dejará avanzar solapadamente, como un rumor de fondo en cuya cuenta cae siempre tarde: relacionarnos acríticamente con nuestros prejuicios significa entrar en una relación de peligrosa domesticidad con todos los contenidos que caen bajo su lupa interesada.

Las retóricas de persuasión son un ensayo de corrección de los efectos de los instrumentos de convergencia. Su intelección del tiempo no las lleva a rellenar con las cuñas del "ya" y el "ahora mismo" el curso victorioso de ninguna historia lineal, ni está orientada a promover en el espiritu del público una angustiosa y arrebatadora sensación de actualidad lista para ser mandada al banquillo (en sentido procesal y futbolistico). Porque hay una soledad que obliga a dejarse conducir por el propio tempo de la obra. A adentrarse en su trópico. Es decir, en la galaxia de sus mediaciones retóricas, en su abisal circuito metafórico, dentro del cual las palabras siempre están a punto de hacer y decir algo distinto de lo que son y dicen en principio y por principios. Y no hay sensación de actualidad que pueda usurpar la importancia que tiene el tiempo interior con que la obra dirige hacia nosotros sus desvíos. Sería excesivamente desolador considerar que el público es una fuerza nacida expresamente para ayudar a que la sensación de actualidad pueda transformar lo trópico en lo tópico.

Por esta razón, puede afirmarse de las retóricas de la persuasión lo mismo que Frye afirmara de la crítica auténticamente valiosa en general: son activamente iconoclastas con respecto a sí mismas. Puesto que, a diferencia de las retóricas de convergencia, aquellas no están dirigidas a realizar el acto de apropiación de la obra de arte en lugar del público, ni patrocinan métodos críticos cuyo objetivo consista en hacer remotas y extrañas al espectador las estructuras imaginarias de las producciones artísticas. Su mayor logro radicará en contrarrestar una doble propensión del público: de un lado, a transformar la obra de arte en un ente distanciado conforme al falso mito del respeto; $y_{1}$ de otro, a ensimismarse en sus propios juicios de valor alargando el carrete de la información publicitaria, que tanto servicio presta a lo que Adorno llamara "nuestros consuelos dominicales".

Si Warburg fue quien propuso hace más de un siglo una "historia cultural de lo social" en lugar de una "historia 
social de la cultura", Walter Benjamin fue el profeta de ese trueque. De la producción de Benjamin hay un título inacabado que resulta decisivo a la hora de analizar la institución económica del público, una obra que alertó como ninguna otra de las compulsiones de la repetición y la alienación con que se quiere capitalizar la presencia masiva de la ciudadanía en el espacio público de la modernidad: La obra de los pasajes. Retengo tan sólo dos centros conceptuales de este libro inmenso, monumento revolucionario al arte de la cita: el fósil y el fetiche.

Benjamin cree que hay una historia que puede ser leida desde la superficie de sus objetos sobrevivientes, la del industrialismo capitalista que en su fase clásica nos legó un mundo de objetos que este paleontólogo marxista de la Belle Époque trata ahora como fósiles. Y hay una idea que subyugó intestinamente a esa historia, la idea de progreso, cuya conversión en una fantasmagoria secular es uno de los materiales más atractivos para la dialéctica benjaminiana (un materialismo de monstruos), tan sensible al modo como las estrategias de temporalización de la modernidad se convirtieron en fetiches.

El espíritu objetivado del capitalismo clásico se manifiesta a la mirada de Benjamin como una naturaleza-inventario llena de fragmentos culturales petrificados (Benjamin, 2005). Efectivamente, Walter Benjamin fue el gran critico de los paisajes petrificados, dolorosos y fallidos, en que la historia ha ido plasmando sus rostros muertos (Benjamin, 2006). Es la misma facies hippocratica del París del Barón de Hausmann, durante el Segundo Imperio, a la que daría un retrato inacabado en la Obra de los pasajes, verdadera historia de la economía material de una época.

La Obra de los pasajes de Benjamin nos dibuja la prehistoria más fascinante de la institución del público moderno: los pasajes, esas galerías comerciales que comenzaron a proliferar a fines del XVIII (hoy algunas lujosamente remozadas, como la Vivienne), que discurren comunicando calles a través de los bajos de edificios del ensanche parisino, expresan ese hábitat antediluviano del consumo burgués organizado a partir de mercancias que se exhiben en escaparates como capillas secularizadas. Pasajes que alguna vez fueron los salones de toda aquella flaneurie que cargaba el tiempo con sus vagabundeos y cuya superdotación visual y enhorabuenas peripatéticas se consiguieron barriendo las iniquidades de la pobreza, expulsando la vida obrera y las insurgencias comuneras del centro de la inmunizada (vale decir, turistizada) ciudad imperial.

El flâneur es, de hecho, el nuevo tipo urbano, protagonista de esa distopía metropolitana de la modernidad, que hizo de él un transeúnte por galerías comerciales y grandes almacenes, como Lafayette, cuya arquitectura remedaba en versión mercantil la de los viejos templos religiosos con sus umbrales, sus pórticos, sus púlpitos, sus cúpulas, sus vitrales, sus deambulatorios y sus capillas, con perfumes en las peanas en lugar de santos y luces eléctricas en lugar de glorias. El flâneur era un urbanita arrojado a una multitud ideológicamente desagregada, echado a una calle políticamente inmunizada, con sus grandes avenidas radiales que volvían ociosas las barricadas. Ambos, multitud y calle, eran las nuevas habitaciones de lo colectivo, asilos de esas soledades que el flâneur mataba a través de la mirada hechizada por los escaparates, desde donde las mercancías ejercían su poder fetichista.

Sumémosle a esta descripción el carácter mortalmente repetitivo del tiempo de progreso, en que la exacerbación de la velocidad a la que se producian los cambios hacía que el sujeto quedase atrapado en una atmósfera miasmática de innovaciones huecas. "El progreso es la huella de Dios mismo", había dicho Víctor Hugo en 1855, bajo el entusiasmo de la primera exposición universal de París. Benjamin examina esa huella. $Y$ ve, en realidad, una fantasmagoría. El progreso, esa huella de Dios según Hugo, se había trasformado en un fetiche: para él, el carácter mortalmente repetitivo del tiempo, que es parte de la arcaica imaginería mítica del infierno, describe lo verdaderamente moderno y novedoso de la sociedad de mercancías. La repetición surge alli donde, como en el mítico infierno, se eterniza hasta el sadismo la búsqueda de innovación. La monotonía se alimenta de lo nuevo, dice Benjamin. Y esta es, en mi opinión, una de las patologías del público.

Frente a esto, las retóricas de la persuasión inciden de forma crítica en la institución del público, impidiendo que se perpetúe el diagnóstico benjaminiano: son índices de resistencia que nos ilustran acerca de cuáles son las presiones, eminentemente políticas, dirigidas a convertir al público en nada más que un capital amortizable. Estas retóricas de la persuasión arrojan, a cambio, cierta inteligencia sobre

ARBOR Vol. 188754 marzo-abril [2012] 409-426 ISSN: 0210-1963 
la dictadura de las modas, a través de las cuales se está programando a cada momento un intercambio fetichista entre cuerpos y mercancias.

Bajo esa comunidad que llamamos público, la sociedad institucionaliza las prácticas del ocio cultural: en resumen, he querido llamar retóricas de la persuasión a todas esas estrategias que nos avisan de que la presencia del público es una producción ideológica, que muchos de los lugares en que se escenifica el ocio cultural son hijos de la megalomanía política. Una buena prueba de que a las clases medias, en la época del imperialismo del "sector servicios", les resulta completamente ajena la desahuciada era industrial, la tenemos en que encuentran encantador que se utilice el término "fábrica" para bautizar grandes centros culturales y de ocio que proliferan por doquier en desmanteladas naves y distritos antaño dedicados a la manufactura, hasta el punto de que es difícil nombrar una capital en el mundo, de Beijing a Madrid, que no tenga un viejo recinto fabril reciclado en una auténtica fábrica de creación.

Las retóricas de la persuasión son ese reservorio de libertad y entendimiento crítico que denuncia la creciente escenificación de las prácticas de ocio cultural en lo que Rem Koolhaas, uno de los arquitectos y urbanistas más lúcidos del presente, ha denominado espacios basura (Junkspace). Ese es el título, precisamente, de uno de sus ensayos, escrito con su retórica más incisiva y fascinante (Koolhaas, 2008): el ocio cultural disfruta hoy de más espacios públicos autoritariamente diseñados, que de verdadera vida pública; se construyen espacios para la experiencia de ocio como nuevos gulags de lujosa y exhibicionista arquitectura, cuya funcionalidad principal no es, como quería Jane Jacobs en su clásico Muerte y vida de las grandes ciudades (Jacobs, 2011), la de atender a ningún sentido dinámico y humanista del intercambio personal, sino la de alumbrar milagrosamente una súbita viabilidad comercial para las ciudades. Todo en nombre de esa nueva galaxia por la que parecen estar absorbidos los vínculos sociales en nuestras depauperadas democracias de consumo, en el trance de reorganizarse como grandes salpicaderos digitales, una galaxia que Koolhaas Ilama Corpotainment ("empretenimiento"), artificioso neologismo resultante de la fusión de dos estrellas que no quieren seguir viviendo solas, la empresa (corporate) y el entretenimiento (entertainment).

\section{EṔ́logo}

"Cualesquiera que sean tus intereses -decia el sociólogo Karl Mannheim-, lo son en cuanto tú eres una persona política; pero el hecho de que tengas intereses de determinada categoría, implica asimismo que es preciso que realices determinados actos para darte cuenta de aquéllos y para conocer la posición especifica que ocupas en el total proceso social" (Mannheim, 1987, 144). Expresado en el lenguaje propio de las retóricas que he venido describiendo: cualquiera que sea la naturaleza de la demanda del público habrá que contar a los instrumentos de convergencia entre sus más enfáticos condicionantes, pues la tendencia a converger, a hacerse actual y uno, a desgobernarse, a hacerse secta, conciliábulo, seguidor, modista, a congregarse aunque sea invisiblemente $y$ en espacios distantes, es sin duda uno de los rasgos definidores de la psique del demandante de obras de arte en la época de su secularización.

En tanto público, somos sin remedio una mezcla del convergente y el persuadido, las dos identidades metafóricas que resultan de exponerse a las retóricas de uno y otro tipo. Ambas funcionan como lenguajes que hablan por nosotros, que saben de nosotros, que nos reúnen y reparten, que pugnan por controlar nuestras respuestas, patrocinando dos modelos distintos de relación entre el arte y la sociedad. No se trata de dos identidades que funcionan la una a espaldas de la otra, moviendo los esqueletos de dos personalidades completamente autónomas. Más bien se trata de metáforas socialmente aplicables a esas dos fuerzas que movilizan de un modo competitivo y simultáneo a nuestra psique cada vez que actuamos como público.

El convergente es el nombre que aquí hemos dado a esa dirección de nuestro psiquismo social que nos lleva a comportarnos como imitadores (el marketing sabe que la imitación más sibilina es la de querer ser diferentes como el otro), como víctimas de esa reputada y tantas veces deliciosa calling of followers contemporánea. Buscadores de la consumibilidad de la oferta cultural y partícipes del calculado esoterismo de la propaganda. Bajo el peso de esta mirada, la obra de arte aparece como un universo de signos hueros; pero al disfrutar de tal universo, el convergente se sitúa en una posición socialmente favorecida y, sobre todo, segura. Es el triunfo de las metáforas institucionales: donde se expone el lado más vulnerable del psiquismo social a 
estructuras simbólicas predigeridas, con las que se establece vínculos controlados a priori, fijos e impersonales, que a cambio ayudan a modelarse una personalidad ventajosa en la gran superficie de las relaciones comunitarias. 0 cómo desvivirnos para poder vivir en paz.

El persuadido (bajo el que se esconde casi siempre un persuasor), aun cuando se enfrente a los mismos productos artísticos, intenta seguir lo que la obra le dice, no por pobreza de su imaginación sino, al contrario, como indispensable y rigurosa condición sine qua non del desarrollo de la naturaleza huidiza, tentadora, asociativa e impredecible de su fantasía hermenéutica. Aquí se levanta un tope crítico ante el avance de las metáforas institucionales: donde la imaginación perturba el orden de significados y los márgenes de convenciones en que se encuentran inicialmente las imágenes. El persuadido, nunca completamente desnudo de las investiduras sociales, de los topes políticos, de las ilusiones del mercado, es un ludópata en sentido etimológico. Aquel que, al intentar hacer justicia a un texto escapando de la tecnocracia de las mesas redondas y de ese nirvana de crédito intelectual que produce la publicidad, cae presa del pathos del juego. Su pasión es el trastrocamiento de todo lo que recibe y todo lo que ama. Para, jugando con ello, salir de sí, atraérselo, y darle un porvenir. Es alguien que se resiste a que su mente sea una pizarra de slogans que, como gritos de guerra de la consumibilidad del arte, lo conviertan en un miembro más de un ejército de muertos. 


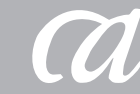

No 754

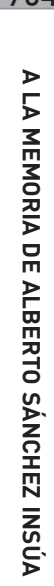

Fotografía 1. MacCapilla.

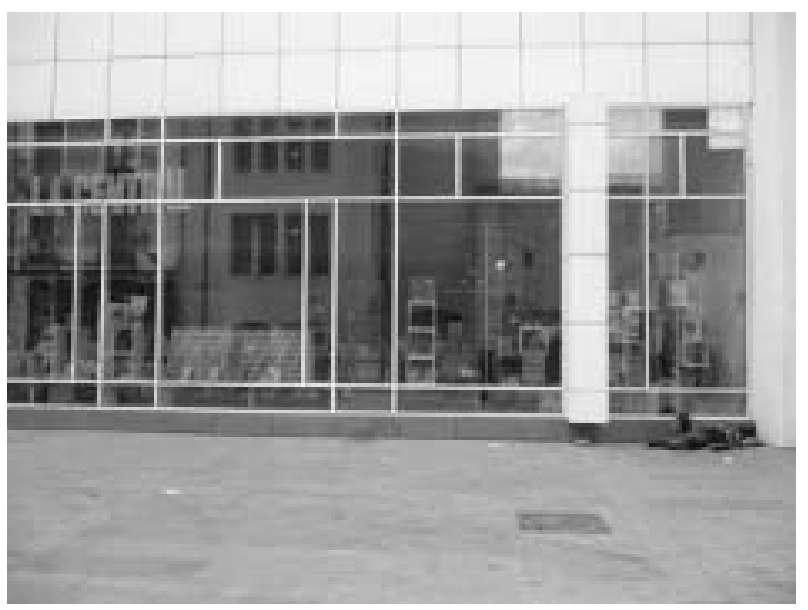

Fotografía 2. Tienda de exposiciones.

Fuente: Fernando Bayón.

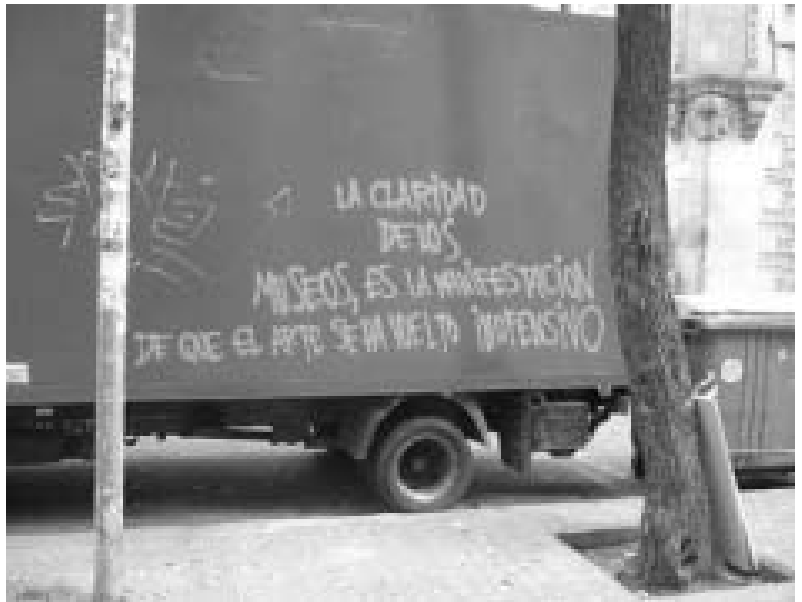

Fotografía 3. Furgonema, hornacina, contenedor.

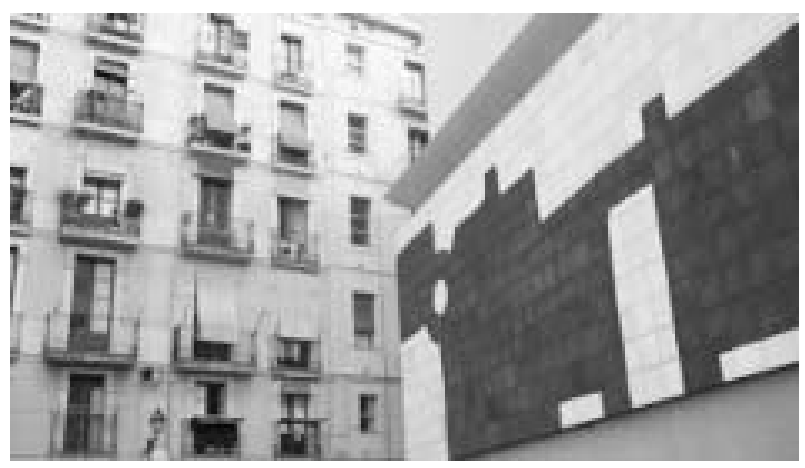

Fotografía 4. Chillida leku. 

Abada.

* Este artículo es resultado de mi participación en el Proyecto de Investigación "Comunidad y violencia: espacios públicos para la construcción de memoria y ciudadanía" (referencia: FFI2011-29869-C02-01/FISO), que dirige Dr. José M. González García.

1 En un libro desopilante que sería al dadaísmo británico lo que fue el "Doctor Faustus" al dodecafonismo alemán, pero sólo en caso de que el dadaísmo británico hubiese existido, Ralph Steadman pone en boca del artista "dudaista" (sic) Gavin Twinge (si, el hombre que encerraba peluches en jaulas): "Arte significa 'hacer'. Algo se hace, pero ¿es arte tal como deseamos definirlo? Da la impresión de que ansiamos una definición, que para Duchamp era una trampa, que es lo que probablemente lo convierte en el artista más importante del siglo XX. Su pregunta, '¿Qué es arte?', quedó sin respuesta, como es lógico, lo cual dio al artista licencia para crear su propio arte: algo que se hace. Algo que es enteramente suyo" (Steadman, 2008, 58).

\section{BIBLIOGRAFÍA}

Adorno, Th. W. (2004): Teoría estética. Obra completa, 7, Madrid, Akal.

Agamben, Giorgio (2008): La potencia del pensamiento, Barcelona, Anagrama.

Baudrillard, Jean (1997): El otro por sí mismo, Barcelona, Anagrama.

Bayón, Fernando (2010): "Nada hace lo que el arte hace. $Y$ otras mentiras en el tiempo de la ruina de la experiencia", en Casas, Armando, et alii (coords.): (Con)fines del arte: reflexiones desde el cine, el psicoa-

Recibido: 11 de mayo de 2011 Aceptado: 13 de julio de 2011
Blanchot, Maurice (2002): La comunidad inconfesable, Madrid, Arena Libros.

Bourdieu, Pierre (1998): La distinción. Criterio y bases sociales del gusto, Madrid, Taurus.

Buck-Morss, Susan (2001): Dialéctica de la mirada. Walter Benjamin y el proyecto de los Pasajes, Madrid, A. Machado libros.

Canetti, Elias (1997): Masa y poder, Madrid, Alianza-Muchnik.

DeLillo, Don (2000): Submundo, Barcelona, Circe.

Didi-Huberman, Georges (2005): Ante el tiempo. Historia del arte y anacronismo de las imágenes, Buenos Aires, Adriana Hidalgo.

- (2009): La imagen superviviente. Historia del arte y tiempo de los fantasmas, Madrid, Abada.

Duque, Félix (2002): La fresca ruina de la tierra. (Del arte y sus desechos), Calima, Palma de Mallorca.

Foucault, Michel (2006): Las palabras y las cosas. Una arqueología de las ciencias humanas, Madrid, Siglo XXI.

Frey, Northrop (1973): La estructura inflexible de la obra literaria. Ensayos sobre crítica y sociedad, Madrid, Taurus.

Ginzburg, Carlo (2008): Mitos, emblemas, indicios. Morfología e historia, BarceIona, Gedisa.

Gombrich, E. H. (1992): Aby Warburg. Una biografía intelectual, Madrid, Alianza.

Jacobs, Jane (2011): Muerte y vida de las grandes ciudades, Madrid, Capitán Swing.

Koolhaas, Rem (2008): Espacio basura, Barcelona, Gustavo Gili.

LaCapra, Dominick (2006): Historia en tránsito. Experiencia, identidad, teoría crítica, Buenos Aires, FCE. 
Luhman, Niklas (2005): El arte de la sociedad, México, Herder/Universidad lberoamericana.

Mannheim, Karl (1987): Ideología y utopía, México, FCE.

Marinas, José Miguel (2006): El síntoma comunitario: entre polis y mercado, Madrid, Machado Libros.
Marx, Karl (2000): El Capital, Madrid, Akal.

Michelstaedter, Carlo (2009): La persuasión y la retórica, Madrid, Sexto Piso.

Sennet, Richard (1977): "Destructive Gemeinschaft", en Birnbaum, Norman, ed.: Beyond the Crisis, Oxford, 0xford University Press.
Steadman, Ralph (2008): Dudá. El arte acrobático de Gavin Twinge, Barcelona, Papel de Liar.

Warburg, Aby (2005): El renacimiento del paganismo. Aportaciones a la historia cultural del Renacimiento europeo, Madrid, Alianza. 